\title{
Smartphone Addiction among University Students and Its Relationship with Academic Performance
}

\author{
Jocelyne Boumosleh ${ }^{1} \&$ Doris Jaalouk ${ }^{1}$ \\ ${ }^{1}$ Department of Nursing and Health Sciences, Notre Dame University-Louaize, Zouk Mosbeh, Lebanon \\ Correspondence: Jocelyne Boumosleh, Faculty of Nursing \& Health Sciences, Notre Dame University-Louaize, \\ P.O.Box 72 Zouk Mikael, Zouk Mosbeh, Lebanon. E-mail: jboumosleh@ndu.edu.lb
}

Received: October 13, 2017 Accepted: November 5, 2017 Online Published: November 20, 2017

doi:10.5539/gjhs.v10n1p48 URL: https://doi.org/10.5539/gjhs.v10n1p48

\begin{abstract}
Background and Objective: Smartphone use is almost universally relied on among college students. Whether smartphone addiction among college students has a negative predictive effect on academic performance is hardly studied. Previous research found an apparent association between smartphone use and academic achievement partly explained by the nature of the task the student is engaged in when using a smartphone. This study aims to assess the relationship between smartphone addiction and students' academic performance controlling for important potential confounding variables.
\end{abstract}

Methods: A sample of 688 undergraduate students was randomly selected from Notre Dame University, Lebanon. Students were asked to fill out a questionnaire that included a) questions on variables related to socio-demographics, academics, smartphone use, and lifestyle behaviors; and b) a 26-item Smartphone Addiction Inventory (SPAI) Scale. Multiple logistic regression was performed to assess the independent association between smartphone addiction and cumulative grade point average (GPA).

Results: $49 \%$ reported smartphone use for at least 5 hours during a weekday. Controlling for confounding effects in the model, the association between total SPAI score and GPA did not reach statistical significance, whereas alcohol drinking $(O R=2.10, p=0.026)$, age at first use of smartphone $(O R=1.20, p=0.042)$, use of smartphone for study-related purposes $(\mathrm{OR}=0.31, \mathrm{p}=0.000)$, class $(\mathrm{OR}=0.35$ (senior vs. sophomore standing), $\mathrm{p}=0.024)$, and faculty (ORs of 0.38 and 0.35 (engineering and humanities, respectively, vs. business students)) were found to be independent predictors of reporting a GPA of $<3$.

Conclusion: Findings from our study can be used to better inform college administrators and faculty about most-at- risk groups of students who shall be targeted in any intervention designed to enhance low academic performance.

Keywords: smartphone addiction, academic performance/grades, university students

\section{Introduction}

A smartphone is "a mobile phone that performs many of the functions of a computer, typically having a touch screen interface, internet access, and an operating system capable of running downloaded applications" (Oxford Dictionaries, 2016). There is no end to the purposes of smartphone applications (apps), with uses ranging from entertainment (gaming, web surfing, and watching/listening to streamed content), communication (connecting to friends, family and coworkers via social media apps or via specialized communication apps for checking one's email, instant messaging, and voice-over-internet protocol calling), to information seeking (finding local and destination information and information related to academic and business pursuits, etc.).

Considering the multi-purpose, mobile, and internet capabilities of a smartphone, it has become a prevalent social phenomenon. According to a survey conducted in 2015 in 40 nations by the Pew Research Center to measure smartphone penetration, Lebanon ranked $16^{\text {th }}$ with $52 \%$ of the population owing a smartphone (Poushter, 2016). A survey conducted by Northwestern University in Qatar from 2013-2016, targeting nationals of six Arab countries, revealed further increase in smartphone penetration in Lebanon (nearly 90\%) in 2016, alongside a dramatic increase in internet penetration (84\%), particularly among 18-24 years old (Northwestern University in Qatar, 2016). Due to the increase in smartphone penetration, smartphone applications offer benefits to the society by offering cost-effective healthcare interventions (Zhang et al., 2014). Nevertheless, excessive usage of smartphone 
to access internet and its applications (e.g. social media) can lead to adverse effects on health.

Nowadays, addiction also refers to behavioral addictions such as gambling, internet gaming, or even smartphone usage. "Pathological gambling", a behavior-related condition, for example, is listed as a diagnosable addictive disorder in a new category on "behavioral addictions" in the fifth edition of the Diagnostic and Statistical Manual of Mental Disorders (DSM-5) (American Psychiatric Association, 2013). In addition, "Internet Gaming Disorder" is listed in DSM-5 as a problematic behavior awaiting more research before considering it as a formal addictive disorder (American Psychiatric Association, 2013). Although internet addiction was not listed in DSM-5, it is recognized that internet addiction has the following symptoms: (1) preoccupation with the internet; (2) need to spend increasing amounts of time online; (3) repeated but unsuccessful attempts to reduce internet use; (4) suffering withdrawal symptoms from reduction of internet use; (5) time management problems; (6) environmental distress from school, family, work, and friends; (7) deception of internet time; and (8) mood modification through internet use (Lai et al., 2013). Smartphone ownership had a significant association with internet addiction (Mak et al., 2014) and smartphone addiction, though also not yet included in the DSM-5, shares similar clinical features as internet addiction and other sorts of addiction (Bian \& Leung, 2015; Kim, Lee, Lee, Nam, \& Chung, 2014; Lee, Cho, Kim, \& Noh, 2015; Lin et al., 2014).

College students are the most rapid adopters of cell phone technology (Smith, Rainie, \& Zickuhr, 2011), and research suggests associations between cell phone use and their health and academic achievement, with the direction of the latter association being partly determined by the nature of the task a student is engaged in when using the cell phone. Researchers, for example, in a cross-sectional study among a sample of undergraduate private college students in the United States (US), found high videogame use to be associated with low grade point average (GPA) (Weaver, Kim, Metzer, \& Szendrey, 2013). Associations between calling and texting, and low self-reported GPA and a self-reported measure of academic difficulty were also found among a sample of first year university students from the US and a sample of Taiwanese female university students, respectively (Hong, Chiu, \& Huang, 2012; Jacobsen \& Forste, 2011). Similarly, in a more recent study done on undergraduate college students from a public US university, a negative association between texting and academic performance was found (Lepp, Barkley, \& Karpinski, 2014). When considering the relationship between use of a cell phone to access a social-networking site and academic achievement, several studies have also identified negative relationships between Facebook use and GPA/ time spent studying (Junco, 2012; Karpinski, Kirschner, Ozer, Mellott, \& Ochwo, 2013; Kirschnera \& Karpinskib, 2010; Stollak, Vandenberg, Burklund, \& Weiss, 2011). On the other hand, using a nationally representative sample from Taiwan, female heavy internet users who particularly favor information seeking and chatting had better academic performance than female non-heavy users, while those favoring information seeking, chatting, and online games had lower average academic grades than female non-heavy users and female heavy users favoring information seeking and chatting. In terms of male students, male heavy internet users favoring online games had lower average academic grades than male non-heavy users and those who especially favor information seeking and chatting (Chen \& Tzeng, 2010). Previous research showed that smartphone and internet addiction were significantly associated with alcohol abuse, depression and anxiety (Ho et al., 2014; Matar Boumosleh \& Jaalouk, 2017), poor sleep quality (Zhang et al., 2017), and quality of life (Tran et al., 2017). These adverse health outcomes have a negative impact on academic studies.

Several researchers speculated that the negative relationship identified between cell phone use and academic performance is moderated by multitasking behavior (use of cell phones for texting, checking social networks, listening to music, web surfing, and playing games, while in class, studying, or doing homework) and therefore attempted to validate this theory by doing quantitative research studies to obtain firm evidence (Becker, Alzahabi, \& Hopwood, 2013; Junco \& Cotten, 2012; Karpinski et al., 2013; Wang \& Tchernev, 2012). In a cross-cultural study involving US and European University students, a negative relationship between the use of social networking sites and GPA, moderated by multitasking, was found in a sample of US students $(n=451)$ (Karpinski et al., 2013). Similar results were obtained from a cross sectional study ( $\mathrm{n}=1774)$ and an intervention study ( $\mathrm{n}=145)$ involving US university students. In the cross sectional study, it was found that sending text messages and checking Facebook while doing schoolwork was negatively related to overall college GPA (Junco \& Cotten, 2012). In the intervention study in which study participants were randomly assigned to multi-tasking with one of four digital technologies (texting using a cell-phone; emailing, MSN messaging, or Facebook search using laptops) or no multitasking (paper-and-pencil note-taking, word-processing note-taking and a natural use of technology condition) while attending class, it was found that students in the Facebook/MSN messaging conditions performed worse/seemed to perform worse on the multiple-choice tests than students in the paper-and-pencil condition, respectively (Wood et al., 2012). Researchers (Bun Lee, 2015; Clayson \& Haley, 2012; Rouis, 2012) who did not find a significant association between multitasking on cell phone and GPA argued, however, against the negative 
effects of multitasking by highlighting the emotional, entertainment, social or specific cognitive benefits of multitasking that other studies failed to consider (Lui \& Wong, 2012; Prabu, Kim, Brickman, Ran, \& Curtis, 2014). Some researchers even argued that academic performance may actually improve with multitasking on cell phone, depending on the nature of the tasks themselves (Grinols \& Rajesh, 2014). It is evident that it is the nonacademic, and not the academic, cell phone multitasking in learning contexts that interferes with a student's learning process, thus negatively affecting his/her academic performance.

Given the exponential increase in smartphone penetration among university students, the association of smartphone ownership with addiction and, therefore, potentially undesirable effects, it becomes important to quantify these effects, especially the effect on the students' academic performance. Almost all previous studies examined the relationship between cell phone use (reasons for use of cell phone (Lepp et al., 2014), multitasking behavior (Karpinski et al., 2013) and minutes of use/day (Bun Lee, 2015; Clayson \& Haley, 2012; Junco \& Cotten, 2012; Lepp et al., 2014; Rouis, 2012; Wood et al., 2012)) and academic performance, with only three cross-sectional studies examining the relationship between risk of smartphone addiction and academic performance or its proxy measures. In a group of females $(n=210)$ selected from a university in Korea, those at low risk for smartphone addiction were found to have higher average self-regulated learning and average learning flow, two proxy measures of academic achievement (Kim, Tak, \& Lee, 2010; Sha, Looi, Chen, \& Zhang, 2012), than those at high/potentially high risk for smartphone addiction (Lee et al., 2015). Another study conducted among 249 students selected from a university in Lebanon also found negative association between GPA and risk of smartphone addiction (Hawi \& Samaha, 2016; Samaha \& Hawi, 2016). In the third study carried among African American US college students ( $\mathrm{n}=304)$, smartphone addiction risk, however, was not found to be significantly associated with GPA, after controlling for multitasking, Facebook addiction and number of hours of studying outside the classroom (Bun Lee, 2015). The latter study was the only study of all three studies to control for some, but not all important, confounders in the relationship between smartphone addiction and academic performance. For example, there is a substantial amount of research over the past decade that says that it is not the amount of time that a student spends online but rather what a student does online which determines the relationship between these variables (Chen \& Tzeng, 2010). Thus, when exploring the impact of smartphone addiction on academic performance of a student, there is a need to consider all important potential confounders including age, sex (Hawi \& Samaha, 2016), age at first use of smartphone (Tsitsika et al., 2014), smoking and alcohol drinking (El Ansari, Stock, \& Mills, 2013), smartphone uses and academic variables (Alam, Arif Billah, \& Alam, 2014). This leads to the following research hypothesis for the current study: Students with high smartphone addiction scores are as likely as students with low addiction scores to have poor academic performance, independent of the aforementioned confounding variables. In other words we speculate that there is no association between smartphone addiction and academic performance after controlling for the aforementioned potential confounding variables.

\section{Methods}

\subsection{Participants}

A sample of 688 undergraduate students was randomly selected from Notre Dame University-Louaize (NDU), Lebanon. Students were recruited from Liberal Art courses (LACs). LACs include a random sample of students from each of NDU's seven faculties.

\subsection{Procedure}

Students were contacted by email to assess their interest in enrollment in the study. Those who expressed interest in participation (92.5\%) were then asked to fill out an online self-administered questionnaire. Data were collected during academic year 2014- 2015.

\subsection{Measures}

The online questionnaire included questions on socio-demographics (age, sex, employment status), academics (cumulative grade-point-average (GPA), class, faculty), smartphone use (age at first use, duration of use on a weekday, reason for use), and lifestyle habits (smoking, alcohol consumption, frequency of religion practice). The question on GPA was as follows (indicate your current cumulative GPA: a. less than or equal to 1.99; b. between 2 and 2.99 ; c. equal to or more than 3.00). GPA is a measure of a student's academic achievement at a college/university; it is calculated on a 4-point grading scale by dividing the total number of grade points earned by the total number of credits attempted, with 4 and 0 being the highest and the lowest achievements, respectively. Excessive smartphone use was defined by 5 hours or more on a weekday (median number of hours of smartphone use on a weekday). The questionnaire also included a 26-item Smartphone Addiction Inventory (SPAI) Scale (Lin 
et al., 2014), that is constructed of four subscales: compulsive behavior, functional impairment, withdrawal and tolerance. The Cronbach's alpha for the total SPAI scale was reported to be 0.94 (Lin et al., 2014).Participants were asked to rate items on a 4-point Likert scale, 1= "strongly disagree", 2= "somewhat disagree"; $3=$ "somewhat agree"; 4= "strongly agree" so that the total SPAI score (addiction score) ranges from 26 to 104. The "strongly disagree", "somewhat disagree" categories were combined into one category called "disagree". Similarly, the "somewhat agree" and the "strongly agree" categories were combined into one category called "agree".

\subsection{Statistical Analysis}

We summarized participants' characteristic using mean \pm standard deviation and $\mathrm{n}(\%)$ for continuous and categorical variables, respectively. Associations between academic performance and continuous/categorical variables were assessed using independent 2-sample T Test (Mann-Whitney-U-test)/ analysis of variance (Kruskal Wallis Test) and the chi square test /Fisher's exact test, respectively. Multiple logistic regression analysis was used to examine the association between smartphone addiction level (total SPAI score) and GPA $(<3$ and $\geq 3)$ after controlling for the effect of confounders. Independent variables that were found, in the bivariate analyses, to be significantly associated with GPA $(p<0.05)$ were entered into the models. Model 1 was unadjusted, showing the main effect of smartphone addiction (total SPAI score-independent variable) on academic performance (dependent variable); model 2 was adjusted for age, sex, and age at first use of smartphone. Model 3 was adjusted for age, sex, age at first use of smartphone, smoking and alcohol drinking. Model 4 was our fully adjusted model in which we additionally controlled for academic-related variables (use of smartphone for study-related purposes, faculty and class). The data were analyzed using the Statistical Package for Social Sciences (SPSS) version 22 for Windows. The level of statistical significance for all tests was set at $\mathrm{p}$-value $<0.05$.

\subsection{Ethical Approval}

The study was carried out in accordance with the Declaration of Helsinki. The study was approved by the Institutional Review Board at Notre Dame University-Louaize (NDU), Lebanon. All subjects were informed about the study's objectives and procedure, and all signed an informed consent.

\section{Results}

The sample included 688 undergraduate students (53\% men and $47 \%$ women) with a mean age of $20.64 \pm 1.88$ years. Participants belonged to all seven faculties, with about $75 \%$ of them reporting to have GPAs of $<3$. About one-third and three-fifths of the students in our sample were smokers and alcohol drinkers, respectively. Their mean age at first use of smartphone and total addiction score (SPAI score) were found to be $15.09 \pm 2.12$ years and $55.37 \pm 15.08$, respectively, with $49 \%$ reporting use for at least 5 hours/weekday. The top three reasons for smartphone use were reported to be texting $(83 \%)$, entertainment/calling family members $(67 \%)$ and calling friends $(62 \%)$ (Table 1$)$. 
Table 1. Characteristics of Study Participants ( $\mathrm{n}=688)$

\begin{tabular}{|c|c|c|}
\hline & n (\%) & $\operatorname{Mean} \pm$ SD (n) \\
\hline Age & & $20.64 \pm 1.88(665)$ \\
\hline \multicolumn{3}{|l|}{ Faculty } \\
\hline Architecture, Arts \& Design & $112(16.7)$ & \\
\hline Business \& Economics & $213(31.8)$ & \\
\hline Engineering & $141(21.0)$ & \\
\hline Humanities & $126(18.8)$ & \\
\hline Law \& Political Sciences & $11(1.6)$ & \\
\hline Natural \& Applied Sciences & $56(8.4)$ & \\
\hline Nursing \& Health Sciences & $11(1.6)$ & \\
\hline \multicolumn{3}{|l|}{ Class } \\
\hline Sophomore (Year 1) & $268(39.4)$ & \\
\hline Junior (Year 2) & $231(33.9)$ & \\
\hline Senior (Year 3) & $182(26.7)$ & \\
\hline \multicolumn{3}{|l|}{ GPA } \\
\hline$\leq 1.99$ & $46(6.7)$ & \\
\hline $2.00-2.99$ & $461(68.4)$ & \\
\hline$\geq 3.00$ & $168(24.9)$ & \\
\hline \multicolumn{3}{|l|}{ Smoking } \\
\hline Yes & $210(33.7)$ & \\
\hline No & $414(66.3)$ & \\
\hline \multicolumn{3}{|l|}{ Alcohol drinking } \\
\hline Yes & $393(62.5)$ & \\
\hline No & $236(37.5)$ & \\
\hline Age at first use of smartphone & & $15.09 \pm 2.12(665)$ \\
\hline Total SPAI Score & & $55.37 \pm 15.08(460)$ \\
\hline \multicolumn{3}{|c|}{ Duration of smartphone use/weekday } \\
\hline 0 to less than 1 hour & $14(2.1)$ & \\
\hline 1 to less than 2 hours & $70(10.3)$ & \\
\hline 2 to less than 3 hours & $55(8.1)$ & \\
\hline 3 to less than 4 hours & $133(19.5)$ & \\
\hline 4 to less than 5 hours & $78(11.5)$ & \\
\hline$\geq$ to 5 hours & $331(48.6)$ & \\
\hline \multicolumn{3}{|l|}{ Reason for using smartphone } \\
\hline Calling family members $(\mathrm{n}=634)$ & $421(67)$ & \\
\hline Calling friends $(\mathrm{n}=634)$ & $387(62)$ & \\
\hline Texting $(\mathrm{n}=634)$ & $519(83)$ & \\
\hline Entertainment $(\mathrm{n}=634)$ & $431(67)$ & \\
\hline Reading News ( $\mathrm{n}=634)$ & $290(46)$ & \\
\hline Other $(\mathrm{n}=634)$ & $164(26)$ & \\
\hline Study-related purposes $(\mathrm{n}=417)$ & $224(54)$ & \\
\hline
\end{tabular}

Lower GPA was found to be significantly associated with older age (GPA 2-2.99: $20.82 \pm 1.94$ vs. GPA $\geq 3$ : $20.32 \pm 1.66$, $\mathrm{p}=0.009)$, male sex (GPA $\leq 1.99$ : M 7.7\% vs. W 5.5\%; GPA $\geq 3$ : M $20.6 \%$ vs. W $29.9 \%$, $\mathrm{p}=0.017$ ), 
sophomore class (GPA $\leq 1.99$ : sophomore $12.7 \%$ vs. junior $4.0 \%$ vs. senior $0.6 \%$; GPA $\geq 3$ : sophomore $20.0 \%$ vs. junior $26.4 \%$ vs. senior $30.9 \%, \mathrm{p}=0.000$ ), smoking (GPA $\leq 1.99$ : smokers $8.7 \%$ vs. non-smokers $5.7 \%$; GPA $\geq 3$ : smokers $15.0 \%$ vs. non-smokers $30.1 \%, \mathrm{p}=0.000)$, alcohol drinking (GPA $\leq 1.99$ : drinkers $6.7 \%$ vs. non-drinkers $6.1 \%$; GPA $\geq 3$ : drinkers $19.6 \%$ vs. non-drinkers $35.5 \%, \mathrm{p}=0.001$ ). Lower GPA was also found to be significantly associated with younger age at first use of smartphone (GPA $\leq 1.99: 14.29 \pm 1.99$ vs. GPA 2-2.99: 15.19 \pm 2.13 , $\mathrm{p}=0.026$ ) and non-use of smartphone for study-related purposes (GPA $\leq 1.99$ : non-users $9.2 \%$ vs. users $5.5 \%$; GPA $\geq 3$ : non-users $20.5 \%$ vs. users $31.4 \%, \mathrm{p}=0.028$ ) (Table 2 ).

Table 2. Associations between Academic Performance and Personal Characteristics and SPAI Score

\begin{tabular}{|c|c|c|c|c|c|c|}
\hline & \multicolumn{3}{|c|}{ GPA [Mean \pm SD (n)] Or n (\%) } & \multirow{2}{*}{$\mathbf{F}$} & \multirow{2}{*}{$\begin{array}{l}\text { df } \\
(B / W)\end{array}$} & \multirow{2}{*}{$\begin{array}{l}\mathbf{p} \\
\text { value }\end{array}$} \\
\hline & $\leq 1.99$ & $2-2.99$ & $\geq 3$ & & & \\
\hline Age & $20.42 \pm 1.82(43)$ & $20.82 \pm 1.94(444)^{*}$ & $20.32 \pm 1.66(154)^{*}$ & 4.768 & 2,648 & 0.009 \\
\hline Sex & & & & & & 0.017 \\
\hline Men & $27(7.7)$ & $251(71.7)$ & $72(20.6)$ & & & \\
\hline Women & $17(5.5)$ & $201(64.6)$ & $93(29.9)$ & & & \\
\hline \multicolumn{7}{|l|}{ Faculty* } \\
\hline Architecture, Arts \& Design & $2(1.8)$ & $82(73.9)$ & $27(24.3)$ & & & \\
\hline Business \& Economics & $27(13.0)$ & $145(70.0)$ & $35(16.9)$ & & & \\
\hline Engineering & $4(2.9)$ & $94(67.6)$ & $41(29.5)$ & & & \\
\hline Humanities & $5(4.1)$ & $77(62.6)$ & $41(33.3)$ & & & \\
\hline Law \& Political Sciences & $1(9.1)$ & $6(54.5)$ & $4(36.4)$ & & & \\
\hline Natural \& Applied Sciences & $3(5.4)$ & $38(67.9)$ & $15(26.8)$ & & & \\
\hline Nursing \& Health Sciences & $1(10.0)$ & $5(50.0)$ & $4(40.0)$ & & & \\
\hline Class & & & & & & 0.000 \\
\hline Sophomore (Year 1) & $33(12.7)$ & $175(67.3)$ & $52(20.0)$ & & & \\
\hline Junior (Year 2) & $9(4.0)$ & $158(69.6)$ & $60(26.4)$ & & & \\
\hline Senior (Year 3) & $1(0.6)$ & $124(68.5)$ & $56(30.9)$ & & & \\
\hline Smoking & & & & & & 0.000 \\
\hline Yes & $18(8.7)$ & $158(76.3)$ & $31(15.0)$ & & & \\
\hline No & $23(5.7)$ & $260(64.2)$ & $122(30.1)$ & & & \\
\hline Alcohol drinking & & & & & & 0.001 \\
\hline Yes & $26(6.7)$ & $285(73.6)$ & $76(19.6)$ & & & \\
\hline No & $14(6.1)$ & $139(60.4)$ & $77(35.5)$ & & & \\
\hline Religion practice & & & & & & 0.472 \\
\hline Daily & $9(7.6)$ & $81(68.1)$ & $29(24.4)$ & & & \\
\hline Once or several times a week & $6(4.2)$ & $104(72.7)$ & $33(23.1)$ & & & \\
\hline Once or several times a month & $6(7.3)$ & $49(59.8)$ & $27(32.9)$ & & & \\
\hline A few times a year & $5(6.2)$ & $52(65.0)$ & $23(28.7)$ & & & \\
\hline Not at all & $4(13.8)$ & $18(62.1)$ & $7(24.1)$ & & & \\
\hline Age at first use of smartphone & $14.29 \pm 1.99(41)^{*}$ & $15.19 \pm 2.13(445)^{*}$ & $15.10 \pm 2.10(167)$ & 3.368 & 2,650 & 0.026 \\
\hline Total SPAI score & $49.00 \pm 14.71(23)$ & $56.10 \pm 15.04(307)$ & $54.72 \pm 15.17(123)$ & 2.529 & 2,450 & 0.081 \\
\hline $\begin{array}{l}\text { Duration of smartphone use } \\
\text { per weekday }\end{array}$ & & & & & & 0.940 \\
\hline$<5 \mathrm{hrs}$ & $22(6.4)$ & $235(68.5)$ & $86(25.1)$ & & & \\
\hline
\end{tabular}




\begin{tabular}{|c|c|c|c|c|}
\hline$\geq 5 \mathrm{hrs}$ & $23(7.1)$ & $222(68.3)$ & $80(24.6)$ & \\
\hline \multicolumn{5}{|l|}{ Reason for using smartphone } \\
\hline $\begin{array}{l}\text { Calling family } \\
(\mathrm{n}=634)\end{array}$ & & & & 0.742 \\
\hline Yes & $27(6.6)$ & $279(67.7)$ & $106(25.7)$ & \\
\hline No & $15(7.4)$ & $142(69.6)$ & $47(23.0)$ & \\
\hline Calling friends $(\mathrm{n}=634)$ & & & & 0.190 \\
\hline Yes & $30(7.9)$ & $251(65.9)$ & $100(26.2)$ & \\
\hline No & $12(5.1)$ & $170(72.3)$ & $53(22.6)$ & \\
\hline Texting $(n=634)$ & & & & 0.363 \\
\hline Yes & $37(7.3)$ & $342(67.2)$ & $130(25.5)$ & \\
\hline No & $5(4.7)$ & $79(73.8)$ & $23(21.5)$ & \\
\hline Entertainment $(\mathrm{n}=634)$ & & & & 0.253 \\
\hline Yes & $25(5.9)$ & $287(67.8)$ & $111(26.2)$ & \\
\hline No & $17(8.8)$ & $134(69.4)$ & $42(21.8)$ & \\
\hline Reading News ( $\mathrm{n}=634)$ & & & & 0.834 \\
\hline Yes & $19(6.7)$ & $192(67.4)$ & $74(26.0)$ & \\
\hline No & $23(6.9)$ & $229(69.2)$ & $79(23.9)$ & \\
\hline Other $(\mathrm{n}=634)$ & & & & 0.148 \\
\hline Yes & $14(8.6)$ & $117(71.8)$ & $32(19.6)$ & \\
\hline No & $28(6.2)$ & $304(67.1)$ & $121(26.7)$ & \\
\hline Study-related purposes $(n=417)$ & & & & 0.028 \\
\hline Yes & $12(5.5)$ & $139(63.2)$ & $69(31.4)$ & \\
\hline No & $17(9.2)$ & $130(70.3)$ & $38(20.5)$ & \\
\hline
\end{tabular}

$*>20 \%$ of cells expected counts of $<5$.

Multiple logistic regression was performed to assess the impact of smartphone addiction level (total SPAI score) on the likelihood that respondents would report that they have a GPA of $<3$, after controlling for the effects of confounding variables. In the unadjusted model (Model 1), smartphone addiction level (total SPAI score) was found to be not significantly associated with GPA. Model 2 contained four independent variables (total SPAI score, age and sex, and age at first use of smartphone). Model 3 was additionally adjusted for lifestyle habits (smoking, alcohol drinking). The full model (Model 4) containing all independent variables (total SPAI score, age, sex, age at first use of smartphone, smoking, alcohol drinking, use of smartphone for study-related purposes, faculty, and class) was statistically significant $\left(\mathrm{X}^{2}=10.69, \mathrm{p}<0.05\right)$, indicating that the model was able to distinguish between respondents who reported and those who did not report a GPA of $<3$. The model as a whole explained between $15.2 \%$ and $21.5 \%$ of the variance in GPA and correctly classified $76.1 \%$ of cases. In the final Model, the odds ratio of about 1.02 for total SPAI score indicates that for a one-point increase in SPAI score, respondents were $2 \%$ more likely to report a GPA of $<3$, controlling for all other factors in the model, but the association did not reach statistical significance $(\mathrm{p}=0.08)$. Five of the independent variables made a unique statistically significant contribution to the model (age at first use of smartphone, alcohol drinking, use of smartphone for study-related purposes, faculty and class), with two of these variables (age at first use of smartphone, alcohol drinking) having positive associations with a GPA of $<3$. Controlling for all other factors in the model, the odds ratio of 1.20 for age at first use of smartphone indicates that for a one-year increase in age at first use of smartphone, respondents were $20 \%$ more likely to report a GPA $<3$, whereas the odds ratio of about 2.10 for alcohol drinking indicates that alcohol drinkers were about 2.1 times more likely to report a GPA of $<3$ than non-alcohol drinkers. Of the remaining three variables that were found to have negative associations with a GPA of $<3$ (use of smartphone for study-related purposes, faculty and class), the strongest predictor of reporting a GPA $<3$ was use of smartphone for study-related purposes, recording an odds ratio of 0.31 ; this indicates that respondents who reported using their 
smartphones for study-related purposes were $69 \%$ less likely to report having a GPA $<3$ than those who did not report using their smartphones for such purposes, controlling for all other factors in the model. The second strongest predictor of reporting a GPA $<3$ was class whereby senior students, compared to sophomore students, were about $66 \%$ less likely to report having a GPA $<3$, controlling for all other factors in the model. Class was followed by faculty. The odds ratios of 0.38 and 0.35 for faculties of Engineering and Humanities indicate that students enrolled in these faculties, compared to Business \& Economics students, were $62 \%$ and $65 \%$ less likely to report having a GPA $<3$, respectively, controlling for all other factors in the model (Table 3).

Table 3. Association between GPA and Total SPAI Score, as Assessed by Multiple Logistic Regression*

\begin{tabular}{|c|c|c|c|c|c|c|c|}
\hline \multirow{2}{*}{ Independent Variables } & \multirow{2}{*}{$\boldsymbol{\beta}$} & \multirow{2}{*}{ S.E. } & \multirow{2}{*}{ P-value } & \multirow{2}{*}{ OR } & \multicolumn{2}{|c|}{ 95\% C.I. for EXP (B) } & \multirow{2}{*}{ R square } \\
\hline & & & & & Lower & Upper & \\
\hline \multicolumn{8}{|l|}{ Model 1} \\
\hline Total Addiction Score & 0.004 & 0.007 & 0.581 & 1.004 & 0.99 & 1.018 & $0.001-0.001$ \\
\hline Model 2 & & & & & & & $0.034-0.050$ \\
\hline Total Addiction Score & 0.006 & 0.008 & 0.396 & 1.006 & 0.992 & 1.021 & \\
\hline Age & 0.208 & 0.071 & 0.003 & 1.232 & 1.072 & 1.415 & \\
\hline Sex & -0.330 & 0.222 & 0.137 & 0.719 & 0.465 & 1.11 & \\
\hline Age at first use of smartphone & -0.008 & 0.059 & 0.897 & 0.992 & 0.884 & 1.114 & \\
\hline Model 3 & & & & & & & $0.067-0.096$ \\
\hline Total Addiction Score & 0.012 & 0.008 & 0.133 & 1.012 & 0.996 & 1.029 & \\
\hline Age & 0.114 & 0.077 & 0.136 & 1.121 & 0.965 & 1.303 & \\
\hline Sex & -0.091 & 0.242 & 0.707 & 0.913 & 0.569 & 1.466 & \\
\hline Age at first use of smartphone & 0.089 & 0.066 & 0.177 & 1.093 & 0.961 & 1.243 & \\
\hline Smoking & 0.526 & 0.302 & 0.082 & 1.692 & 0.936 & 3.06 & \\
\hline Alcohol drinking & 0.615 & 0.257 & 0.017 & 1.849 & 1.117 & 3.063 & \\
\hline Model 4 & & & & & & & $0.152-0.215$ \\
\hline Total Addiction Score & 0.019 & 0.011 & 0.077 & 1.019 & 0.998 & 1.041 & \\
\hline Age & 0.199 & 0.115 & 0.084 & 1.220 & 0.974 & 1.530 & \\
\hline Sex & -0.059 & 0.321 & 0.855 & 0.943 & 0.503 & 1.768 & \\
\hline Age at first use of smartphone & 0.184 & 0.091 & 0.042 & 1.202 & 1.006 & 1.436 & \\
\hline Smoking & 0.627 & 0.381 & 0.100 & 1.872 & 0.887 & 3.954 & \\
\hline Alcohol drinking & 0.740 & 0.333 & 0.026 & 2.096 & 1.091 & 4.024 & \\
\hline $\begin{array}{l}\text { Use of smartphone for study-related } \\
\text { purposes }\end{array}$ & -1.163 & 0.333 & 0.000 & 0.313 & 0.163 & 0.601 & \\
\hline \multicolumn{8}{|l|}{ Faculty $^{\wedge}$} \\
\hline Engineering & -0.957 & 0.456 & 0.036 & 0.384 & 0.157 & 0.938 & \\
\hline Humanities & -1.046 & 0.475 & 0.028 & 0.351 & 0.139 & 0.691 & \\
\hline Other & -0.621 & 0.396 & 0.117 & 0.538 & 0.247 & 1.169 & \\
\hline \multicolumn{8}{|l|}{ Class $^{\wedge}$} \\
\hline Junior (Year 2) & -0.574 & 0.376 & 0.127 & 0.563 & 0.269 & 1.178 & \\
\hline Senior (Year 3) & -1.064 & 0.473 & 0.024 & 0.345 & 0.137 & 0.872 & \\
\hline
\end{tabular}

*: Dependent Variable: GPA.

^: Reference group: Faculty (Business \& Economics), Class (Sophomore).

\section{Discussion}

We did not find smartphone addiction score to have an association with academic performance (GPA), independent 
of the effects of age, sex, age at first use of smartphone, smoking, alcohol drinking, smartphone use for study-related purposes, faculty and class in our sample. Our study finding resonates with findings of previous research studies that made similar attempts. In a study done on a sample of 304 African American college students (mean age $=22.45$ years), smartphone addiction risk did not predict academic performance, after controlling for the effects of multitasking, Facebook addiction and number of hours of studying outside the classroom (Bun Lee, 2015). Also, though academic stress level showed significant positive correlation with smartphone addiction, it had no direct predictive effect on smartphone addiction, as per findings from a survey among 387 university students from Taiwan. In addition, there was no direct or indirect link between learning self-efficacy and smartphone addiction (Chiu, 2014). On the contrary, three studies that examined this relationship without controlling for the effects of confounding variables found a positive link between the two variables. In a sample of 249 Lebanese students (mean age $=20.96$ years), smartphone addiction risk had statistically significant negative correlation with academic performance (Samaha \& Hawi, 2016). Besides, subjects identified as high risk for smartphone addiction had statistically significant lower odds of achieving distinctive academic performance (GPA 23.2) compared to those identified as low risk for smartphone addiction (Hawi \& Samaha, 2016). The third study conducted among a 210 Korean female university students (mean age $=22$ years) showed that high smartphone addiction risk group rated low on measures of self-regulated learning using smart devices, and learning flow, compared to general user group (Lee et al., 2015). Apparently, academic performance has no independent/direct relationship with smartphone addiction. It may be that high frequency cell phone users, in comparison to low frequency users, use their smartphones for purposes that ultimately improve their academic performance (academic-related purposes, entertainment through playing games that sharpen certain cognitive skills) (Bun Lee, 2015).

This study makes several important contributions to the existing literature. This study is the first, to our knowledge, to use a more holistic approach to examining the association between smartphone addiction level and academic performance, by attempting to control for the effects of multiple important potential confounders in this relationship: age, sex (Hawi \& Samaha, 2016), age at first use of smartphone (Tsitsika et al., 2014), smoking and alcohol drinking (El Ansari et al., 2013), smartphone uses and academic variables (Alam et al., 2014). Because smartphones constitute a new technology, the availability of prior research exploring the impact of smartphone addiction on academic performance is almost non-existent. Only three studies examined the relationship between smartphone addiction and academic performance, with all assessing smartphone addiction risk, rather than smartphone addiction (Bun Lee, 2015; Hawi \& Samaha, 2016; Lee et al., 2015; Samaha \& Hawi, 2016), and only one assessing the independent association, while controlling for the effects of a restricted set of confounding variables (Facebook addiction, multitasking behavior and the number of hours spent studying outside the classroom) (Bun Lee, 2015). Besides, the tool that we used for assessing smartphone addiction has been used and was validated among university students' samples (Lin et al., 2014).

While these contributions are new, there are limitations to consider. First, the study design was cross-sectional so identified associations between age at first use of smartphone, alcohol drinking, use of smartphone for study related purposes, faculty, class and academic performance cannot be inferred as causal. Future longitudinal studies are needed to elucidate the temporal and therefore the causal relationship between university students' smartphone addiction level and their academic performance. Second, data on the variables (dependent (GPA) and independent) were self-reported hence, may possibly bear some inaccuracies. In addition, reporting bias for not wanting to reveal vulnerabilities (even if data collection forms did not bear student's personal identifiers and were not collected in person by the researchers) or recall bias (academic performance, time spent and reason for using smartphone during a weekday, age at first use of smartphone) may have occurred. Third, the sample consisted of only undergraduate students enrolled at a single, private university in Lebanon; hence our study findings cannot be generalized to the population of private university students as well as the population of public university students in Lebanon. In addition, while in the US, undergraduate, graduate and young non-students were found to use the internet on a cell phone and social networking sites at roughly similar rates, and young US adults (students and non-students) were found to be more likely to do so than the overall adult population (Smith et al., 2011), we cannot assume that these findings also apply to the Lebanese population. Fourth, this study did not recruit medical students. The prevalence of internet addiction among medical students is approximately five times than that of the general population (Zhang, Lim, Lee, \& Ho, 2017a). As a result, it is worthwhile to assess how smartphone addiction affects academic performance of medical students because they need high attention and concentration for future patient care after graduation. Fifth, this study did not report other important reasons for using smartphone. Young people spend a lot of time on Facebook and similar social media platforms (Zhang et al., 2017b) which contribute to smartphone addiction. 


\section{Future Implications}

This research has important implications for administrators, faculty and students in higher education institutions. Evidence from this study suggests that low academic performance is associated with alcohol drinking, enrollment in business and economics programs, first year in college, and non-use of smartphone for academic purposes. Higher education administrators and governmental officials should develop and test interventions ( for. e.g. awareness campaigns) designed to enhance the academic performance of students who are vulnerable to have low GPAs such as alcohol drinkers, sophomore and business students, eliminate smartphone phone use by students for non-academic purposes while attending a class or studying alone and encourage students to use their smartphone in a smart way by choosing to do entertainment activities that sharpen their cognitive skills.

There is certainly a need for more research. Experimental studies could be conducted to examine the relationship between a specific task a student is involved in whenever using the smartphone (for e.g., calling/texting friends for inquiries related/not related to one's studies, playing cognitive/non-cognitive games) and academic performance. In addition, future research in Lebanon should target different populations including university students (graduate and undergraduate) from public and private universities and school students.

\section{Competing Interests Statement}

The authors declare that they have no conflict of interest.

\section{References}

Alam, M., Arif Billah, M., \& Alam, M. (2014). Factors affecting academic performance of undergraduate students at International Islamic University Chittagong (IIUC), Bangladesh. Journal of Education and Practice, 5(39), 143-154.

American Psychiatric Association. (2013). Internet Gaming Disorder. American Psychiatric Association DSM-V Development. $\quad$ Retrieved August $\quad 30, \quad 2016, \quad$ from http://www.dsm5.org/Documents/Internet\%20Gaming\%20Disorder\%20Fact\%20Sheet.pdf

American Psychiatric Association. (2013). Substance-Related and Addictive Disorders. American Psychiatric Association DSM-V Development. Retrieved August 30, 2016, from http://www.dsm5.org/documents/substance\%20use\%20disorder\%20fact\%20sheet.pdf

Becker, M., Alzahabi, R., \& Hopwood, C. (2013). Media multitasking is associated with symptoms of depression and social anxiety. Cyberpsychology, Behavior and Social Networking, 16(2), 132-135. https://doi.org/10.1089/cyber.2012.0291

Bian, M., \& Leung, L. (2015). Linking loneliness, shyness, smartphone addiction symptoms, and patterns of smartphone use to social capital. Social Science Computer Review, 33(1), 61-79. https://doi.org/0.1177/0894439314528779

Bun Lee, E. (2015). Too much information: Heavy smartphone and Facebook utilization by African American young adults. Journal of Black Studies, 46(1), 44-61. https://doi.org/0.1177/0021934714557034

Chen, S., \& Tzeng, J. (2010). College female and male heavy internet users' profiles of practices and their academic grades and psychosocial adjustment. Cyberpsychology, Behavior and Social Networking, 13(3), 257-262. https://doi.org/10.1089/cyber.2009.0023

Chiu, S. (2014). The relationship between life stress and smartphone addiction on Taiwanese university student: A mediation model of learning self-efficacy and social self-efficacy. Computers in Human Behavior, 34, 49-57. https://doi.org/10.1016/j.chb.2014.01.024

Clayson, D., \& Haley, D. (2012). An introduction to multitasking and texting: Prevalence and impact on grades and GPA in marketing classes. Journal of Marketing Education, 35(1), 26-40. https://doi.org/10.1177/027347531246733

El Ansari, W., Stock, C., \& Mills, C. (2013). Is alcohol consumption associated with poor academic achievement in university students? International Journal of Preventive Medicine, 4(10), 1175-1188.

Grinols, A., \& Rajesh, R. (2014). Multitasking with smartphones in the college classroom. Business and Professional Communication Quarterly, 77(1), 89-95. https://doi.org/10.1177/2329490613515300

Hawi, N., \& Samaha, M. (2016). To excel or not to excel: Strong evidence on the adverse effect of smartphone addiction on academic performance. Computers \& Education, 98, 81-89.

Ho, R. C., Zhang, M. W., Tsang, T. Y., Toh, A. H., Pan, F., Lu, Y., ... \& Mak, K. K. (2014). The association 
between internet addiction and psychiatric co-morbidity: a meta-analysis. BMC Psychiatry, 14,183. https://doi.org/10.1186/1471-244X-14-183

Hong, F., Chiu, S., \& Huang, D. (2012). A model of the relationship between psychological characteristics, mobile phone addiction and use of mobile phones by Taiwanese university female students. Computers in Human Behavior, 28(6), 2152-2159. https://doi.org/10.1016/j.chb.2012.06.020

Jacobsen, W., \& Forste, R. (2011). The wired generation: academic and social outcomes of electronic media use among university students. Cyberpsychology, Behavior and Social Networking, 14, 275-280. https://doi.org/10.1089/cyber.2010.0135

Junco, R., \& Cotten, S. (2012). No A 4 U: The relationship between multitasking and academic performance. Computers \& Education, 59(2), 505-514. https://doi.org/10.1016/j.compedu.2011.12.023

Junco, R. (2012). Too much face and not enough books: The relationship between multiple indices of Facebook use and academic performance. Computers in Human Behavior, 28(1), 187-198. https://doi.org/10.1016/j.chb.2011.08.026

Karpinski, A., Kirschner, P., Ozer, I., Mellott, J., \& Ochwo, P. (2013). An exploration of social networking site use, multitasking, and academic performance among United States and European university students. Computers in Human Behavior, 29(3), 1182-1192. https://doi.org/10.1016/j.chb.2012.10.011

Kim, A., Tak, H., \& Lee, C. (2010). The development and validation of a learning flow scale for adults. Educational Psychology Research, 39-59.

Kim, D., Lee, Y., Lee, J., Nam, J., \& Chung, Y. (2014). Development of Korean smartphone addiction proneness scale for youth. PLoS One, 9(5), e97920. https://doi.org/10.1371/journal.pone.0097920

Kirschner, P., \& Karpinski, A. (2010). Facebook and academic performance. Computers in Human Behavior, 26(6), 1237-1245. https://doi.org/10.1016/j.chb.2010.03.024

Lai, C. M., Mak, K. K., Watanabe, H., Ang, R. P., Pang, J. S., \& Ho, R. C. (2013). Psychometric properties of the internet addiction test in Chinese adolescents. Journal of Pediatric Psychology, 38, 794-807. https://doi.org/10.1093/jpepsy/jst022

Lee, J., Cho, B., Kim, Y., \& Noh, J. (2015). Smartphone addiction in university students and its implication for learning. In G. Chen, V. Kumar, H. R. Kinshuk, \& S. Kong (Eds.), Emerging Issues in Smart Learning. Springer-Verlag. https://doi.org/10.1007/978-3-662-44188-6_40

Lepp, A., Barkley, J., \& Karpinski, A. (2014). The relationship between cell phone use, academic performance, anxiety, and satisfaction with life in college students. Computers in Human Behavior, 31, 343-350. https://doi.org/10.1016/j.chb.2013.10.049

Lin, Y., Chang, L., Lee, Y., Tseng, H., Kuo, T., \& Chen, S. (2014). Development and validation of the Smartphone Addiction Inventory (SPAI). PLoS One, 9(6), e98312. https://doi.org/10.1371/journal.pone.0098312

Lui, K., \& Wong, A. (2012). Does media multitasking always hurt? A positive correlation between multitasking and multisensory integration. Psychonomic Bulletin \& Review, 19(4), 647-653. https://doi.org/10.3758/s13423-012-0245-7

Mak, K. K., Lai, C. M., Watanabe, H., Kim, D. I., Bahar, N., Ramos, M., ... \& Cheng, C. (2014). Epidemiology of internet behaviors and addiction among adolescents in six Asian countries. Cyberpsychology, Behavior and Social Networking, 17, 720-728. https://doi.org/10.1089/cyber.2014.0139

Matar Boumosleh, J., \& Jaalouk, D. (2017). Depression, anxiety, and smartphone addiction in university studentsA cross sectional study. PLoS One, 12(8), e0182239. https://doi.org/10.1371/journal.pone.0182239

Northwestern University in Qatar. (2016). Media use in the Middle East, 2016: Online and social media. Retrieved March 23, 2017, from http://www.mideastmedia.org/survey/2016/chapter/online-and-social-media/

Oxford Dictionaries. (n.d.). Definition of smartphone in English. Retrieved August 2016, from http://www.oxforddictionaries.com/definition/english/smartphone

Poushter, J. (2016). Smartphone ownership and Internet usage continues to climb in emerging economies. Pew Research Center. Retrieved March 2016, from http://www.pewglobal.org/2016/02/22/smartphone-ownership-and-internet-usage-continues-to-climb-in-em erging-economies/

Prabu, D., Kim, J., Brickman, J., Ran, W., \& Curtis, C. (2014). Mobile phone distraction while studying. New 
Media \& Society. https://doi.org/10.1177/1461444814531692

Rouis, S. (2012). Impact of cognitive absorption on Facebook on students' achievement. Cyberpsycholoy, Behavior and Social Networking, 15(6), 296-303. https://doi.org/10.1089/cyber.2011.0390

Samaha, M., \& Hawi, N. (2016, Apr). Relationships among smartphone addiction, stress, academic performance, and satisfaction with life. Computers in Human Behavior, 57, 321-325. https://doi.org/10.1016/j.chb.2015.12.045

Sha, L., Looi, C., Chen, W., \& Zhang, B. (2012). Understanding mobile learning from the perspective of self-regulated learning. Journal of Computer Assisted Learning, 28, 366-378. https://doi.org/10.1111/j.1365-2729.2011.00461.x

Smith, A., Rainie, L., \& Zickuhr, K. (2011). College students and technology. Pew Research Center. Retrieved March 2016, from http://www.pewinternet.org/2011/07/19/college-students-and-technology/

Stollak, M., Vandenberg, A., Burklund, A., \& Weiss, S. (2011). Getting social: The impact of social networking usage on grades among college students. Proceedings of ASBBS Annual Conference, 18, pp. 859-865.

Tran, B. X., Huong, L. T., Hinh, N. D., Nguyen, L. H., Le, B. N., Nong, V. M., ...\& Ho, R. C. (2017). A study on the influence of internet addiction and online interpersonal influences on health-related quality of life in young Vietnamese. BMC Public Health, 17, 138. https://doi.org/10.1186/s12889-016-3983-z

Tsitsika, A., Janikian, M., Schoenmakers, T., Tzavela, E., Olafsson, K., Wojcik, S., . . Richardson, C. (2014). Internet addictive behavior in adolescence: A cross-sectional study in seven European countries. Cyberpsychology, Behavior and Social Networking, 17(8), 528-535. https://doi.org/10.1089/cyber.2013.0382

Wang, Z., \& Tchernev, J. (2012). The "myth" of media multitasking: Reciprocal dynamics of media multitasking, personal needs, and gratifications. Journal of Communication, 62, 493-513. https://doi.org/10.1111/j.1460-2466.2012.01641.x

Weaver, J., Kim, P., Metzer, R., \& Szendrey, J. (2013). The impact of video games on student GPA, study habits, and time management skills: What's the big deal? Issues in Information Systems, 14(1), 122-128. Retrieved March 2016, from http://iacis.org/iis/2013/184_iis_2013_122-128.pdf

Wood, E., Zivcakova, L., Gentile, P., Archer, K., De Pasquale, D., \& Nosko, A. (2012). Examining the impact of off-task multi-tasking with technology on real-time classroom learning. Computers \& Education, 58, 365-374. https://doi.org/10.1016/j.compedu.2011.08.029

Zhang, M. W., Lim, R. B., Lee, C., \& Ho, R. C. (2017a). Prevalence of internet addiction in medical students: A meta-analysis. Academic Psychiatry. https://doi.org/10.1007/s40596-017-0794-1

Zhang, M. W., Tran, B. X., Huong, L. T., Hinh, N. D., Nguyen, H. L., Tho, T. D., ...\& Ho, R. C. (2017). Internet addiction and sleep quality among Vietnamese youths. Asian Journal of Psychiatry, 28, 15-20. https://doi.org/10.1016/j.ajp.2017.03.025

Zhang, M. W., Tran, B. X., Le, H. T., Nguyen, H. D., Nguyen, C. T., Tran, T. D., ... \& Ho, R. C. (2017b). Perceptions of health-related information on Facebook: Cross-sectional study among Vietnamese youths. Interactive Journal of Medical Research, 6(2):e16. https://doi.org/10.2196/ijmr.8072

Zhang, M. W., Tsang, T., Cheow, E., Ho, C. S., Yeong, N.B., \& Ho, R. C. (2014). Enabling psychiatrists to be mobile phone app developers: Insights into app development methodologies. JMIR Mhealth and Uhealth, 11, e53. https://doi.org/10.2196/mhealth.3425

\section{Copyrights}

Copyright for this article is retained by the author(s), with first publication rights granted to the journal.

This is an open-access article distributed under the terms and conditions of the Creative Commons Attribution license (http://creativecommons.org/licenses/by/4.0/). 